\section{Heuschnupfen scheint vor Rheuma zu schützen}

\section{Schon längere Zeit wurde vermutet, daß Patienten mit Allergien} weniger oft oder weniger stark ausgeprägt an anderen Immunkrankheiten leiden. Eine neue Untersuchung erhärtet diesen Verdacht. Ihr Ergebnis: Heuschnupfenpatienten erkranken seltener an einer rheumatoiden Arthritis als andere Menschen.

Die rheumatoide Arthritis (RA) ist vermutlich eine Autoimmunerkrankung. Genau weiß man das nicht, da die Autoantigene noch nicht gefunden wurden. Fest steht jedoch, daß T-(Helfer-) Zellen bei der Entzündung eine Rolle spielen. In der Gelenkflüssigkeit ist vor allem die Aktivität der TH-1-Zellen erhöht, feststellbar an einer vermehrten Bildung von Tumornekrosefaktor $\alpha$ (TNF $\alpha)$. Das TH-2-Zytokin Interleukin 4 wird dagegen nicht vermehrt gebildet. Aus allergologischer Sicht sind dies verkehrte Welten, denn bei atopischen Erkrankungen ist typischerweise die TH-2-Antwort erhöht, man spricht auch von einem TH-1- zu TH2-Switch.

Dies brachte Catharina Verhoef von der Universität Utrecht auf die Idee zu prüfen, ob die TH-2-Dominanz bei einer atopischen Erkrankung möglicherweise vor einer RA schützt. Sie befragte deshalb 304 an der Klinik behandelte Patienten mit RA, ob sie ,zufällig“ auch an allergischer Rhinitis litten. Die Diagnose wurde mittels Hauttest und Bestimmung des spezifischen IgEs gesichert. Als Kontrollgruppe dienten 339 Patienten mit nicht-rheumatischen Erkrankungen.

Tatsächlich war die Prävalenz eines Heuschnupfens bei RA-Patienten nur halb so hoch wie in der Kontrollgruppe (4\% versus $8 \%$ ). Außerdem hatten die 12 Patienten mit RA und gleichzeitigem Heuschnupfen deutlich weniger Symptome als die nicht-allergischen Rheumatiker. Kritisch anzumerken ist

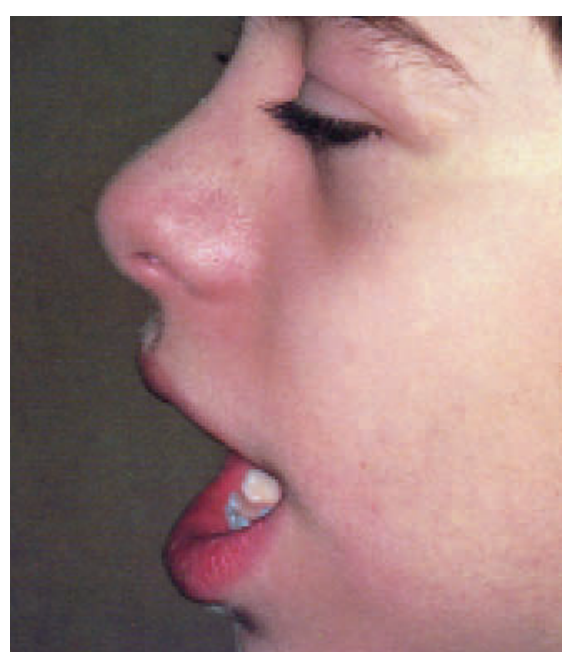

Kleiner Trost für Rhinitispatienten: Autoimmunkrankheiten werden bei ihnen seltener als bei anderen Menschen auftreten.

die relativ unscharfe Charakterisierung der Kontrollgruppe.

Es ist nicht die erste Untersuchung, die auf einen gegenseitigen Ausschluß von Immunerkrankungen/Phänomenen und Allergien hinweist. So konnte kürzlich gezeigt werden, daß Patienten mit multipler Sklerose seltener an IgEmediierten Allergien erkranken (J Allergy Clin Immunol 1996; 97: 1402-8) und in Japan erkranken Kinder mit einem positiven Tuberkulintest seltener an Asthma (Science 1997; 275: 77-9). Ob hieraus einmal therapeutische Konsequenzen abgeleitet werden können, ist offen.

(rme)

Verhoef CM: Mutual antagonism of rheumatoid arthritis and hay fever; a role for type 1/type 2 T cell balance. Ann Rheum Dis 1998; 57: 275-80.

\section{Asthmatikerinnen:} Häufige

Notfallaufnahmen in der perimenstruellen Phase

Asthmaattacken bei Frauen in der perimenstruellen Phase sind häufig so schwerwiegend, daß eine Klinikeinweisung erforderlich wird - so das Ergebnis einer prospektiven Studie.

Im Rahmen dieser Studie führten 32 asthmakranke Frauen über 6 Zyklen ein Asthmatagebuch. Täglich trugen sie ihre Symptomatik, den Medikamentenbedarf sowie die Ergebnisse ihrer Messung mit dem PeakFlow-Meßgerät ein.

Die Auswertung der so gesammelten Daten ergab, daß Frauen, die über eine Verschlechterung der Asthmabeschwerden während der Menstruation oder um den Menstruationszeitraum herum klagten, im Durchschnitt älter als andere Asthmatikerinnen waren.

Diese Frauen waren auch länger an Asthma erkrankt, hatten einen signifikant schlechteren Peak-Flow und benötigten deutlich größere Mengen an Notfallmedikamenten als Frauen, deren Asthmaattacken über alle Phasen des Zyklus gleich verteilt waren. Am stärksten waren die Asthmaattacken, wenn sie in den Tagen 1 bis 4 nach Beginn der Menses auftraten.

Die Studie bestätigt frühere Untersuchungen, nach denen es bei vielen Frauen in der perimenstruellen Phase zu einem deutlichen Anstieg der Asthmaattacken kommt. Amerikanischen Zahlen zufolge entfallen drei Viertel aller Notfallaufnahmen wegen Asthma auf Frauen.

(rme)

Shames RS: Clinical differences among women with and without self-reported perimenstrual asthma. 